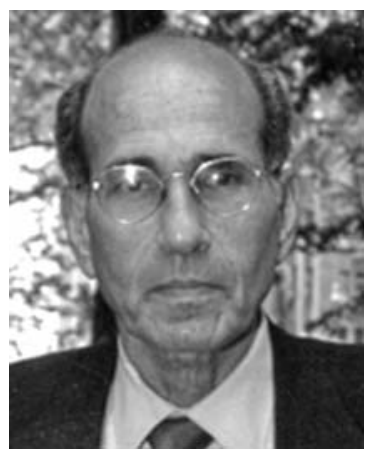

\title{
A Conversation with Richard Axel
}

\author{
INTERVIEWER: KAREN CARNIOL \\ Deputy Editor, Cell
}

Richard Axel is University Professor and Investigator at the Howard Hughes Medical Institute, College of Physicians and Surgeons of Columbia University.

Karen Carniol: You are interested in how odor is represented in the brain. One of the things you've been talking about recently is the difference between innate odors and how they're represented, and learned odors and how they're represented.

Dr. Axel: A small number of odors elicit innate, aversive, appetitive, social, and sexual behaviors, but most odors are not innate. The valence of most odors is learned. I think it's reasonable to believe that innate odors are mediated by neural circuits put in place in response to predictive cues that have existed over long periods of evolutionary time. Learned odors, on the other hand, are elicited, we believe, by ensembles of neurons that are reinforced to acquire meaning over the life of an organism.

What we've been able to demonstrate is that olfactory information, once it leaves the first relay, the olfactory bulb pentafurcates - that is, splits into five. One of the regions it projects to is the cortical amygdala, which we've shown is both necessary and sufficient to elicit innate behaviors. Another of the projections goes to the olfactory cortex, piriform cortex, and we believe that ensemble is not innately determined, and that the ensemble is required for learned olfactory behavior.

Karen Carniol: There's perhaps a clearer degree of functional plasticity in the piriform than would be seen in the amygdala?

Dr. Axel: Yes, that's a very elegant consequence of the way the piriform representation is generated. We believe that this representation is generated by virtue of receiving inputs from random combinations of glomerular low SI in this first relay of the bulb. If the presentation is indeed random, it can have no meaning. Meaning must be imposed by experience. The system is set up to require this plasticity in order to elicit a learned behavior.

Of course, the enormous benefit of this is that a representation is generated and it has no inherent bias with respect to behavioral output. It has no valence. If valence is imposed by learning, this allows the organism not only to respond to the universe of odors, but to be able to respond in a way that allows an appropriate behavioral response to an often very variable and unpredictable world.

Karen Carniol: One of the striking observations on olfactory nerve projections is the topographical organization at the first layer of the olfactory bulb. Was it surprising to you that that's lost when the piriform is reached? Or does it make sense that this organization is preserved globally even though the meaning it might have imposed at the next level is going to be lost?

Dr. Axel: Yes, being an amateur neuroscientist, I was struck by the fact that the piriform discards this order so early in the pathway. I think that inputs from random sources to neurons and sensory cortices will be seen more generally, not just in the piriform cortex. I think we'll see it in higher stations of sensory cortices. In piriform, you see it after two synapses.

But I was certainly surprised by the finding and it forced us to think about what advantages it affords the organism. In fact, if you model a random representation, as we have with Larry Abbott at Columbia, there are many advantages to random inputs that would not be observed with more structured inputs.

Karen Carniol: Have you encountered people who disagree with your interpretation of random inputs and imposition of meaning?

Dr. Axel: I've encountered more people who question our interpretation than agree with it, but gradually that's beginning to shift as more data emerge. Their argument is that in the olfactory bulb, a given odor activates a stereotype spatial pattern of neural activity, and we don't see that in piriform. We see distributive activity. All odors give a dispersed pattern of neural activity which is interdigitating different odors.

There's no discernible order, so critics argue that I do not know the true natural salient odor mixtures that are relevant to the organism. If I could identify those, I would see a maintenance of order in some form. But every effort 
we've made to discern odors or mixtures of odors that would restore order have failed. We've tried to address the criticisms.

Karen Carniol: Since the topic of this meeting is cognition, do you think innate cognition exists or is that an oxymoron?
Dr. Axel: I think that the way in which the brain thinksthat is, the material of cognition-is likely to be innate. There's something probably uniquely human about the materials we use. By materials, I mean the neural circuits that we use to think, to carry out what some people call cognition. I'm incapable of it but the rest of the world does it very well. 


\section{$\$_{\text {CSH }}^{\infty}$ Cold Spring Harbor Symposia SYMPOSIA On Quantitative Biology}

\section{A Conversation with Richard Axel}

Cold Spring Harb Symp Quant Biol 2014 79: 258-259

Access the most recent version at doi:10.1101/sqb.2014.79.03

\section{License}

Email Alerting Receive free email alerts when new articles cite this article - sign up in Service the box at the top right corner of the article or click here. 